\title{
A Study on the CMR Criteria for Domestic Petroleum Stream
}

\section{UVCB Substances}

\author{
Minji Kwon $^{1 \oplus} \cdot$ Meejin Kang ${ }^{2 \odot} \cdot$ Keunwon Lee $^{1} \cdot$ Seungho Jung, ${ }^{1+\oplus}$ \\ ${ }^{1}$ Department of Environmental \& Safety Engineering, Ajou University \\ ${ }^{2}$ Ministry of Environment
}

(Received October 6, 2020; Revised November 16, 2020; Accepted December 1, 2020)

\begin{abstract}
Objectives: According to a revised version of the K-REACH, a registration grace period was granted for each recorded tonnage of toxic materials. At this time, 364 hazardous substances, such as carcinogens, mutagens, and agents that cause reproductive toxicity, were announced to be registered by 2021 , even if the number of reported tonnage were low. Some petroleum stream substances were excluded from the list due to complications in identifying their compositions. Especially for petroleum UVCB substances, which have varying amounts of ingredients and contents.
\end{abstract}

Methods: A list of domestic petroleum substances is made by researching petroleum substances regulated abroad. The status of domestic and foreign management of the substance was investigated and a method for determining the CMR of petroleum substances is suggested.

Results and Discussion: A list of petroleum substances has been compiled. Five methods for CMR determination of petroleum substances, then the currently applicable method has been proposed.

Conclusions: By preparing a list for the management of petroleum substances and criteria for CMR judgment, it is expected that even before the test data or epidemiological data of the relevant substance are secured, it can be used for safety management in advance by predicting the hazard.

Keywords: K-REACH, Petroleum Substances, CMR, UVCB, Management of Hazardous Chemicals 


\title{
연구논문
}

\section{국내 석유계 UVCB 물질의 CMR 판단 기준에 관한 연구}

\author{
권민지 $^{1 \odot} \cdot$ 강미진 $^{2 \odot} \cdot$ 이근원 $^{1} \cdot$ 정승호 $^{1+\uparrow}$ \\ ${ }^{1}$ 아주대학교 환경안전공학과 \\ 2환경부
}

목적:「화학물질등록평가법(이하 화평법)」의 개정에 따라 기존화학물질에 대하여 등록 톤수별로 등록 유예기간을 부여받았으며, 발암성, 변이원성 및 생식독성 등 유해성이 높은 물질(이하 고유해성물질)은 등록톤수가 낮더라도 21년까지 등록하게 되었다. 그러나 석유공정 및 석유화학공정에서 취급되는 화학물질(이하 석유계 화학물질)로써 구성성분이 복잡한 일부 물질들에 대해서는 구성성분 확인의 어려움 등 여러 이유로 21 년까지 등록해야 할 고유해 성 물질의 목록에서 제외되었다. 이에 성분·함량이 일정하지 않은 석유계 복합다성분물질(UVCB)에 대해서는 그 제조공정 등을 고려하여 $\mathrm{CMR}$ 물질 여부를 판단하는 기준을 제시하고자 한다.

방법: 국외에서 규제하는 석유계 화학물질을 조사하여 국내 석유계 화학물질 목록을 작성하고, 해당 물질의 국내· 외 관리현황을 조사했다. 또한, 석유계 화학물질의 발암성, 변이원성 및 생식독성 여부를 판단할 수 있는 기준을 제시하였다.

결과 및 토의: 국내·외 석유계 화학물질의 관리현황을 조사해 석유계 화학물질 목록을 마련했으며, 발암성 등 유해 성을 판단하기 위한 5 가지 방법을 도출한 후, 이 중 현재 적용 가능한 방법을 제안했다.

결론: 석유계 화학물질 관리를 위한 목록과 $\mathrm{CMR}$ 판단 기준을 마련함으로써 해당 물질의 시험자료나 역학자료가 확보되기 이전이라도 유해성을 예측하여 안전관리 계획을 수립하는데 활용될 수 있을 것으로 기대한다.

주제어: 화평법, 석유계 화학물질, 발암성·변이원성 및 생식독성, 유해화학물질 관리, UVCB

\section{1. 서론}

2019년 화평법이 개정되면서 등록해야 할 기존화학물질* 의 범위가 확대되었다. 기존화학물질의 등록에 관하여, 등 록하여야 하는 대상 범위는 유해성 심사 또는 위해성 평가 를 하기 위하여 등록할 필요가 있다고 인정하여 환경부 장 관이 고시한 등록대상 기존화학물질(종전 화평법상 고시된 510 종)에서 연간 1 톤 이상 제조·수입하는 모든 기존화학물 질이다. ${ }^{1)}$ 다만, 기존화학물질을 제조·수입하려는 자가 제조 또는 수입 전에 환경부 장관에게 화학물질명, 취급량, 분류 표시 등을 신고(이하 사전신고)하는 경우 톤수 범위에 따른 등록 유예기간 동안 등록을 하지 아니하고 제조·수입할 수 있다. 즉, 연간 천 톤 이상 제조·수입하는 경우 2021년까지 등록하여야 하고, 연간 1톤 이상 10 톤 미만이면 2030년까지

\footnotetext{
* 1991년 2월 2일 이전 국내에서 상업용으로 유통된 상업용 화학물질과 1991년 2월 2일 이후 종전의「유해화학물질 관리법 에 따라 유해성 심사를 받은 화학물질로써 환경부 장관이 고시한 물질.
}

등록하도록 연간 제조·수입하는 톤수 범위에 따라 등록유 예 기간을 차등 적용하고 있다. 한편 국민건강 및 환경보호 를 위해 발암성, 변이원성 및 생식독성(CMR; Carcinogenic, Mutagenic, Reproductive)물질(이하, 'CMR물질')로 알려진 기존화학물질은 연간 제조·수입량이 적더라도 조기에 유해 성정보를 확보할 필요성이 제기되었다. 이에 따라 환경부 장관은 연간 제조·수입량이 적더라도 조기에 유해성 정보 를 확보할 필요가 있는 물질 364종을 고시(환경부 고시 제 2018-232호)하고, 이 목록에 해당하는 물질을 연간 1톤 이상 제조·수입할 경우 2021년까지 등록하도록 하였다. ${ }^{2)}$

Clark et al.(2013) $)^{3)}$ 의 연구에서 석유계 물질 중 대부분은 그 성분·함량이 항상 일정한 값을 나타내지 않아 다성분혼 합물로 정의하기 곤란한 물질(이하 $\mathrm{UVCB}^{* *}$ 물질)이다. 그 러나 현재 고시된 $\mathrm{CMR}$ 물질에는 일부 '석유계 및 석탄계 화학물질(이하 석유계 화학물질)' 중 $\mathrm{UVCB}$ 물질은 포함되

\footnotetext{
** Substance of Unknown or Variable composition, Complex reaction products or Biological materials, 이하 UVCB.
} 


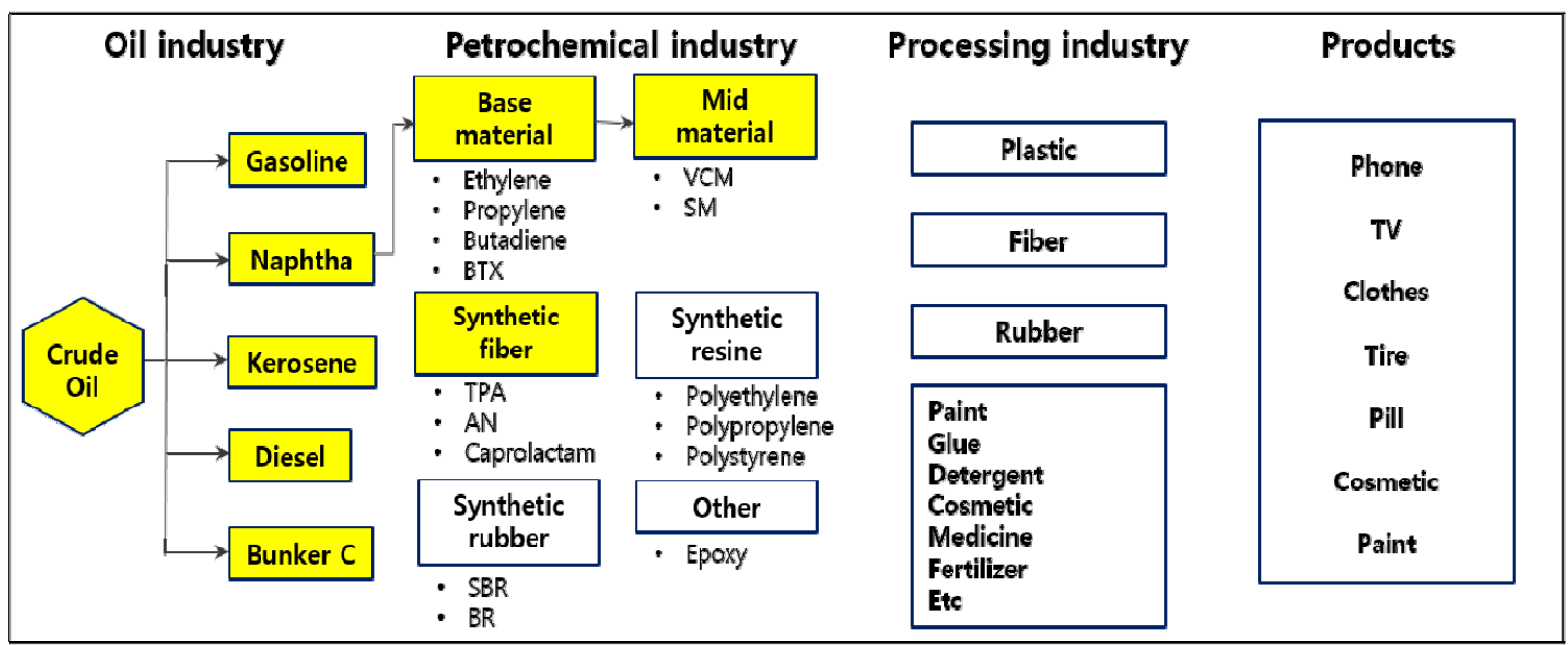

Fig. 1. Range of petroleum chemicals.

어 있지 않다. 이는 현재 국내에선 UVCB 물질에 해당하는 석유계 화학물질(이하 석유계 $\mathrm{UVCB}$ 물질)에 대한 목록 및 공정에 대한 구체적인 사항이 확인되지 않아 석유계 $\mathrm{UVCB}$ 물질 중 인체에 심각한 영향을 줄 수 있는 $\mathrm{CMR}$ 물질을 판 단하고 관리하는 데 제한점이 있기 때문이다.

또한, 세계적으로 동물시험이 제한되며 국내·외에서 $\mathrm{QSAR}^{*}$ 를 이용해 UVCB 물질의 $\mathrm{CMR}$ 여부를 알아보려는 연구는 진행되고 있다. 그러나 UVCB 물질은 구조를 특정 지을 수 없는 특성상 현재 기술 수준에서는 현실적으로 적용 불가능함 을 Moon et al. (2020)를 통해 알 수 있다. 이처럼 현재 UVCB 물질의 특성상 $\mathrm{CMR}$ 구분은 직접 및 간접적인 방법을 통해 어렵다는 것을 알 수 있다.

우리나라에서는 CMR 물질의 등록 규제에 따라 석유계 물질의 CMR 판단 기준 마련이 필요하다. 따라서 실제 국외 의 관리 사례를 바탕으로 국내에 적용 가능한 석유계 $\mathrm{UVCB}$ 물질의 $\mathrm{CMR}$ 판단 기준과 활용방안을 제시하고자 했다.

\section{2. 연구대상 및 방법}

\section{1. 연구대상}

석유계 화학물질이란, 원유를 증류·정제하여 분리하거나 여러 가지 반응을 거쳐 얻어지는 물질로서 원유정제공정, 석유화학 공정 등의 원료 또는 제품으로 얻어지는 물질이 다. 이러한 화학물질 중 본 연구에서는 “석유계 화학물질" 의 범위를 석유정제 공정에서 취급되는 원료, 부원료, 제품 (공정의 산출물 등) 등에 해당하는 화학물질부터 석유화학 제품 중 기초원료, 중간원료 및 합성섬유 원료를 포함(합성

* 구조-활성의 정량적 관계(Quantitative structure-activity relationship, QSAR)모델은 화학, 생물학, 공학에서 사용되는 회귀 또는 분류모델로 화학구조와 예측하고자 하는 활성 간의 정량적인 수학적 모델을 말한다.
수지, 합성고무, 기타제품 제외)한 물질까지를 말하며 앞으 로 “석유계 화학물질”로 표현할 것이다(Fig. 1).

\section{2. 연구 방법}

본 연구에서는 석유계 화학물질을 관리하는 국외 선행제 도를 응용하여 국내에 적용 방안을 제시하고자 했다. 먼저, 관리방안 제시에 앞서 관리의 대상을 정했다. 유럽과 미국 의 화학물질 목록을 바탕으로 국내 통계조사 또는 기존화학 물질 고시 또는 사전 신고된 기존화학물질 목록 등을 추가 하여 국내 석유계 화학물질 목록을 작성했다. 목록 내 물질 을 대상으로 국내외 관리현황, 국내 사전신고 현황, 국내 유 해화학물질 대상 여부, 국외의 석유계 범주(Category) 분류 현황, 국외 규제에 의한 $\mathrm{CMR}$ 여부 등 국내·외 관리현황을 조사하였다.

또한, 국내 석유계 화학물질 중 $\mathrm{CMR}$ 가능성을 판단하 기 위해 국내 석유계 화학물질 제조공정을 확인할 필요가 있었다. 그러나 국내에서 보편적으로 사용될 수 있는 대 표적인 계통도가 없었고, 앞서 마련한 물질목록을 토대로 국내 계통도를 작성했다. 이를 위해 미국 OSHA의 기술지 침(Technical Manual)에서 제공하는 석유정제공정(Petroleum Refining Process) 계통도를 응용하여 앞서 마련했던 목록의 물질에 대하여 제조 특성, 탄소수 범위, 끓는점 범위 등을 참고하여 계통도를 작성했다. 계통도의 각 공정, 공정과 공 정 사이의 노선에 번호를 부여하여 석유계 화학물질들의 계 통도상 위치를 파악했다.

그리고 본 연구의 핵심인 석유계 $\mathrm{UVCB}$ 물질의 $\mathrm{CMR}$ 판 단 기준을 마련하기 위해 지표가 되는 기준물질의 포함 여 부를 판단하는 방법과 탄화수소의 유형(사슬형, 고리형 등) 과 탄소수 범위를 기준으로 하는 범주에 따른 경향성을 통 해 판단하는 방법을 제시했다. 
Table 1. Keywords used to screen substances.

\begin{tabular}{|c|c|}
\hline Step & Keywords \\
\hline $1 \mathrm{st}$ & $\begin{array}{l}\text { ethylene, propylene, butadiene, benzene, toluene, } \\
\text { xylene }\end{array}$ \\
\hline 2nd & distillate, extract, residue, ect., $x->c ., c=,>c$ \\
\hline $3 r d$ & petroleum, coal, cracked \\
\hline 4 th & $\begin{array}{c}\text { paraffin, mineral oil, petrolatum, wax, naphtha, } \\
\text { diesel, hydrocarbon oil }\end{array}$ \\
\hline
\end{tabular}

\section{3. 결과 및 고찰}

\section{1. 국내 석유계 화학물질 목록 작성 및 현황조사}

\subsection{1. 국내·외 석유계 화학물질 목록 작성}

화평법 제 2 조의 제 3 호에 따른 기존화학물질로 고시된 물 질(44,476종)을 기반으로 화학물질명을 통해 석유계 화학물 질로 추정되는 총 1,234 종을 추출하고, 대한석유협회 회원 사가 사용하는 물질 중 연간 1,000 톤 이상 제조·수입하는 물질 96종을 취합하여 국내 석유계 화학물질 목록을 작성 하였다. ${ }^{5)}$

국외 석유계 화학물질은 유럽의 ECHA에 등재된 물질 (22,268종) 중 석유계 화학물질로 추정되는 물질 642 종, $\mathrm{PETCO}$ 그룹에서 보유한 석유·석탄계 물질 846종 그리고 미국의 TSCA 물질(68,091종) 중 석유계 화학물질로 추정되 는 271종과 HPV 챌린지 프로그램에서 제공하는 석유계 화 학물질 391종을 취합하여 국외 석유계 화학물질 목록을 작 성하였다. ${ }^{6-12)}$

그리고 국내외 물질목록을 모두 합한 뒤 중복된 물질을 제거하여 총 1,785 종의 국내·외 석유계 화학물질목록을 작 성하였다. 이때 석유계 화학물질 여부를 추정할 때 사용한 키워드는 다음 표와 같다(Table 1).

\subsection{2. 국내·외 석유계 화학물질 목록 현황 조사}

작성된 총 1,785 종의 국내·외 석유계 화학물질에 단일물 질, 다성분물질, $\mathrm{UVCB}$ 물질 및 국내 기존화학물질 해당 여 부, 기존화학물질 사전신고 여부('19.6.30. 기준)를 확인하 고, 환경부 고시 '21년까지 등록하여야 할 $\mathrm{CMR}$ 물질 및 사 고대비물질, 제한물질, 금지물질, 중점관리물질 해당 여부를 확인하였다.

$\mathrm{EU}$ REACH 등록 여부, CLP 규정 ANNEX VI에 따른 $\mathrm{CMR}$ 분류 또는 $\mathrm{EU} \mathrm{REACH}$ 등록 시 산업계에서 제출한 분 류정보, 미국의 HPV 해당 여부를 확인하였고, PETCO Group 인 CONCAWE, LOA, HOPA, HSPA, R4CC에서 석유계 화 학물질을 분류하고 있는 범주도 확인했다. 또한, 유해성 여 부를 파악하기 위해 국내·외 공개된 정보를 토대로 고유해 성(CMR(구분1)) 해당 여부를 파악하였다.

국내 정보에서는 국립환경과학원 고시 '유독물질 지정'에 따른 유독물질 해당 여부와 '화학물질 분류 및 표시 등에
Table 2. EU CLP regulation notes (ANNEX VI).

\begin{tabular}{l} 
The classification as a carcinogen or mutagen need not \\
apply if it can be shown that the substance contains less \\
than $0.1 \% \mathrm{w} / \mathrm{w}$ benzene. (EINECS No 200-753-7) Applying \\
only to certain complex coal- and oil-derived substances \\
\hline The classification as a carcinogen or mutagen need not \\
K apply if it can be shown that the substance contains less \\
than $0.1 \% \mathrm{w} / \mathrm{w} 1,3-$ butadiene. (EINECS No 203-450-8) \\
Applying only to complex oil-derived substances
\end{tabular}

The classification as a carcinogen need not apply if it can be

shown that the substance contains less than $0.005 \% \mathrm{w} / \mathrm{w}$ benzo[a]-pyrene.(EINECS No 200-028-5) Applying only to complex coal-derived substances.

The classification as a carcinogen need not apply if the full

refining history is known and it can be shown that the substance from which it is produced is not a carcinogen. Applying only to complex oil-derived substances

The classification as a carcinogen or mutagen need not

P apply if it can be shown that the substance contains less than $0.1 \%$ w/w benzene. (EINECS No 200-753-7) Applying only to complex oil-derived substance

관한 규정(국립환경과학원 고시)' [별표 4] '분류·표시 목록' 을 토대로 발암성, 생식세포 변이원성, 생식독성을 확인하 였고, 고용노동부 고시 '화학물질 및 물리적 인자의 노출 기 준'에 따른 [별표 1] '화학물질의 노출기준'을 토대로 발암 성, 생식세포 변이원성, 생식독성을 확인하였다. ${ }^{13-15)}$

국외 정보에서는 European Commission에서 CLP 규정에 따라 고시한 Annex VI (이하, 'ANNEX VI')에는 4,264종의 화학물질에 대한 유해성 분류(항목별 구분 값), 표시사항(그 림문자, 신호어, 유해·위험 문구), $\mathrm{CMR}$ (구분1) 여부를 판단 할 수 있는 정보(Notes) ${ }^{16}($ Table 2) 등이 수록되어 있어서 해 당 정보를 분석하여 국내·외 석유계 화학물질에 대한 $\mathrm{CMR}$ 분류 가능성을 우선 확인하였다. EU CLP 규정 ANNEX VI 에 분류정보가 없는 화학물질은 $\mathrm{EU} \mathrm{REACH}$ 등록 시 업체 가 제출한 CLP 분류결과를 고려하여 국내외 석유계 화학물 질에 대한 $\mathrm{CMR}$ 분류를 확인하였다.

또한, 국제 발암물질을 규제하는 국제기구 또는 국제기관 인 NTP, IRIS, ACGIH, IARC에서 제공하는 정보를 토대로 발암성, 생식세포 변이원성, 생식독성을 확인하였다.

\subsection{3. 국내·외 석유계 화학물질의 분류}

앞에서 정리된 결과를 토대로, 총 1,785 종의 석유계 화학 물질을 국내·외 $\mathrm{CMR}$ 분류정보 확인결과에 따라 총 4 개의 그룹으로 그룹화하였다. 각 그룹에 대한 분류 기준은 다음 표와 같다(Table 3). 


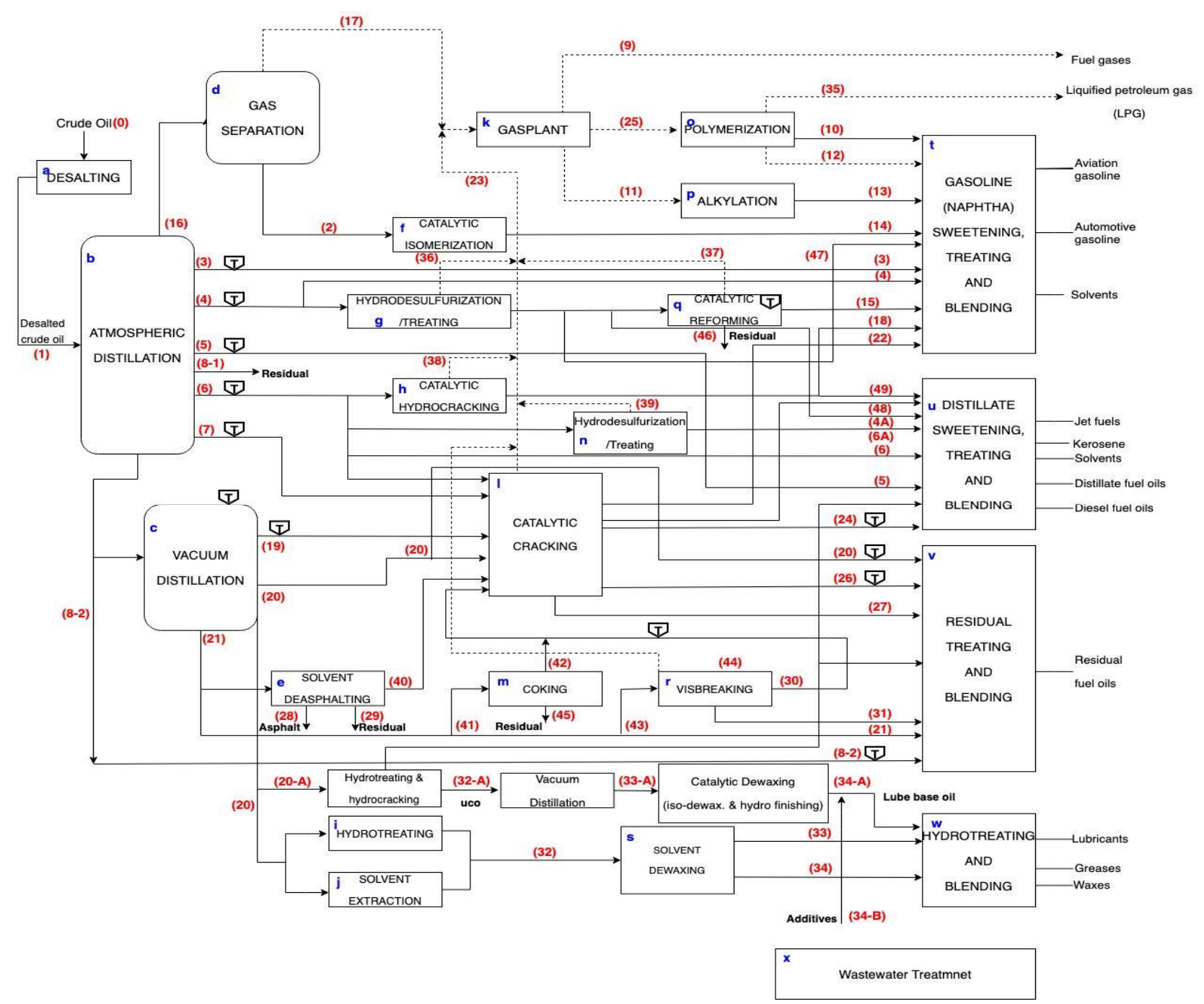

Fig.2. Modified petroleum refinery process diagram.

Table 3. Grouping according to the results of CMR classification information.

\section{Group}

\section{Contents}

EU CLP regulation ANNEX VI CMR (Category 1), NTP 'Known', IRIS 'A', ACGIH 'A1', IARC '1', National Institute of Environmental Research notice '1 (1A, 1B)', Ministry of Employment and Labor notice '1 (1A, 1B)'

Except Group A, EU CLP regulation ANNEX VI CMR (Category 2), NTP 'RAHC', IRIS 'B1, B2, C', ACGIH 'A2, A3',

Group B IARC '2A, 2B', National Institute of Environmental Research notice '2', Ministry of Employment and Labor notice '2', not classified as CMR (Category 1)

Group C Except Group A and B, Classified as CMR (Category 1) upon EU REACH registration

Group D Except Group A, B and C, Cannot be classified based on the obtained information

\subsection{OSHA 계통도를 활용한 국내 계통도 작성}

국내·외 석유계 화학물질 목록에서 UVCB에 해당한 물질 중 EC Description*이 있고 OSHA 계통도에 적용 가능한 기초유분 전 단계까지에 해당하는 물질 총 822 종에 대해 $\mathrm{EC}$ description 상 끓는점, 탄소수, 점도 등의 정보와 범주, 물질명을 통해 계통도상 어느 곳에서 해당 물질이 배출되는 지 파악해 최종 567 종의 물질을 적용한 새로운 계통도를 작 성했다. ${ }^{17)}$

계통도에 기존의 OHSA 계통도에서 넘버링 되어있는 라 인은 그대로 유지하고 각 공정을 알파벳 소문자 순서대로 이름을 부여한 뒤, 석유계 $\mathrm{UVCB}$ 물질은 각 물질의 $\mathrm{EC}$ Description을 토대로 물질이 어떤 공정(알파벳 소문자)이나, 어떤 라인(숫자)에서 나오는지 표시했다(Fig. 2).

\footnotetext{
* 유럽화학물질청(ECHA)에서 제공하는 화학물질 목록(EC Inventory)에 서 물질특성을 설명한 것.
} 
Table 4. CONCAWE total number of substances by category \& CMR substances ratio (\%).

\begin{tabular}{|c|c|c|c|c|c|c|}
\hline \multirow{2}{*}{ No. } & \multirow{2}{*}{ Category } & \multicolumn{5}{|c|}{ Number of substances (\%) } \\
\hline & & Total & Group A & Group B & Group C & Group D \\
\hline & Total & 412 & $322(78.2)$ & $33(8.0)$ & $1(0.2)$ & $56(13.6)$ \\
\hline 1 & Bitumen & 7 & - & $2(28.6)$ & - & $5(71.4)$ \\
\hline 2 & Cracked Gas Oils & 10 & $9(90.0)$ & - & - & $1(10.0)$ \\
\hline 3 & Foots Oils & 6 & $6(100)$ & - & - & - \\
\hline 4 & Heavy Fuel Oil Components & 36 & $36(100)$ & - & - & - \\
\hline 5 & Highly Refined Base Oils & 2 & - & - & - & $2(100)$ \\
\hline 6 & Kerosines & 22 & - & $22(100)$ & - & - \\
\hline 7 & Low Boiling Point Naphthas (Gasolines) & 116 & $113(97.4)$ & $1(0.9)$ & - & $2(1.7)$ \\
\hline 8 & Other Gas Oils & 27 & $27(100)$ & - & - & - \\
\hline 9 & Other Lubricant Base Oils & 81 & $78(96.3)$ & - & - & $3(3.7)$ \\
\hline 10 & Oxidised Asphalt & 1 & - & $1(100)$ & - & - \\
\hline 11 & Paraffin and Hydrocarbon Waxes & 22 & - & - & - & $22(100)$ \\
\hline 12 & Petrolatums & 7 & $7(100)$ & - & - & - \\
\hline 13 & Residual Aromatic Extracts & 2 & - & - & - & $2(100)$ \\
\hline 14 & Slack Waxes & 10 & $10(100)$ & - & - & - \\
\hline 15 & Straight-run Gas Oils & 9 & - & - & $1(11.1)$ & $8(88.9)$ \\
\hline 16 & Sulfur & 1 & - & $1(100)$ & - & - \\
\hline 17 & Treated Distillate Aromatic Extracts & 18 & $18(100)$ & - & - & - \\
\hline 18 & Unrefined / Acid Treated Oils & 12 & $12(100)$ & - & - & - \\
\hline 19 & Untreated Distillate Aromatic Extracts & 6 & $6(100)$ & - & - & - \\
\hline 20 & $\begin{array}{l}\text { Vacuum Gas Oils, Hydrocracked Gas Oils } \\
\text { \& Distillate Fuels }\end{array}$ & 17 & - & $6(35.3)$ & - & $11(64.7)$ \\
\hline
\end{tabular}

\section{3. $\mathrm{CMR}$ 판단 기준 제시}

\subsection{1. 범주 구분을 통한 $\mathrm{CMR}$ 물질 판단}

\subsubsection{1. 국내 계통도를 활용한 판단}

앞에서 작성한 계통도 3 번 라인 31 개의 물질은 모두 $\mathrm{UVCB}$ 물질로써 이 중 그룹A 물질 14 개이고, 이 중 $45 \%$ 가 $\mathrm{CMR}$ 물질로써 어떠한 물질이 이 라인에서 배출된다면 $\mathrm{CMR}$ 가능성을 지닌다고 추측할 수 있다. 그 외의 나머지 물질 17 개는 그룹D에 속하며 국내·외 기준에 따라 CMR로 분류되지 않았기에 직접 $\mathrm{CMR}$ 여부를 판단해야 한다. 이처 럼 계통도를 통해 물질에 대한 $\mathrm{CMR}$ 여부를 간접적으로 확 인할 수 있으므로, 이를 통해 시험자료 등이 확보되기 전이 라도 그에 맞는 안전관리가 가능할 것으로 판단된다. 그러 나 물질목록 총 1,785 종에 대해 EC Description이 없는 물질 이 더 많으며, 있다고 하더라도 해당 정보만으로 계통도에 적용하는 데 어려움이 있어 567 종의 물질만을 가지고 계통 도를 작성했기에 이를 활용하는데 한계점이 있다.

\subsubsection{PETCO Group 범주를 통한 판단}

국외 석유 및 석탄계 화학물질 취급자 단체·협회 기관인 CONCAWE, LOA, HOPA, HSPA, R4CC에서 CMR(구분1) 로 이미 분류한 물질이 있으므로, 이들 물질이 5 개 기관에
서 분류하고 있는 범주별 화학물질 중 어디에 주로 포함되 어 있는지를 확인하고 이에 따라 해당 범주에 속한 $\mathrm{UVCB}$ 물질을 $\mathrm{CMR}$ (구분1)의 가능성이 매우 높은 물질로 구분하 는 방안을 마련했다. 만일 범주 자체의 CMR 우려를 판단할 수 있다면, 아직 어떤 범주에 해당하는지 분류되지 않은 $\mathrm{UVCB}$ 물질이더라도 각 범주별 주요 특성에 부합한다면 이 를 통해 미리 안전관리가 가능할 것으로 기대된다.

CONCAWE에서 구분하고 있는 범주별 총 물질 수 및 이 중 $\mathrm{CMR}$ (구분1)로 분류되는 물질 수를 확인했다(Table 4).

CONCAWE에서는 412 종의 석유계 화학물질을 20 개 범주 로 구분하고 있으며, 이 중 가장 많은 물질이 존재하는 'LOW BOILING NAPHTHAS'를 보면 범주에 속하는 116종의 물질 중 113 종이 그룹A로 분류되어 있으며 이 범주 중 $97.4 \%$ 가 $\mathrm{CMR}$ 물질이다. 이를 통해 해당 범주에 속하면 $\mathrm{CMR}$ 일 가능 성이 크다는 것을 추측할 수 있다.

다만, 고유해성 범주의 주요 특성에 부합하는 화학물질이 더라도 제조공정이나 출발물질 내에 $\mathrm{CMR}$ 등 고유해성 물 질의 함유 정도에 따라 각각의 화학물질은 $\mathrm{CMR}$ 등 유해성 이 낮을 수 있고, 반대로 유해성이 높지 않은 범주의 주요 특성에 부합하는 화학물질 중 유해성이 높은 화학물질이 있 을 수 있어, 범주 구분을 통한 판단에는 불확실성이 있다. 
Table 5. Priority among harmful factors subject to work environment measurement.

\begin{tabular}{cccc} 
Priority & Chemical name & CAS No. & $\begin{array}{c}\text { No. } \\
\text { Company }\end{array}$ \\
\hline 1 & Formaldehyde & $50-00-0$ & 1,153 \\
\hline 2 & Benzene & $71-43-2$ & 503 \\
\hline 3 & Acrylonitrile & $107-13-1$ & 196 \\
\hline 4 & $1,3-B u t a d i e n e$ & $106-99-0$ & 140 \\
\hline 5 & Ethylene oxide & $75-21-8$ & 75 \\
\hline 6 & $1,2-$ Dichloroethane & $107-06-2$ & 62 \\
\hline 7 & 1,2-Epoxypropane & $75-56-9$ & 61 \\
\hline 8 & Vinyl chloride & $75-01-4$ & 34 \\
\hline
\end{tabular}

\subsection{2. 구성 성분에 따른 $\mathrm{CMR}$ 물질 판단}

\subsubsection{EU CLP ANNEX VI에 제시된 성분에 따른 판단}

$\mathrm{EU}$ CLP 규정 ANNEX VI의 판단 기준에 따르면 CMR (구분1)로 구분된 UVCB 물질의 경우, "특정 물질을 특정 함량기준 미만”으로 함유하고 있다면, 해당 $\mathrm{UVCB}$ 물질은 $\mathrm{CMR}$ 물질이 아닌 것으로 판단하고 있다.

이처럼 $\mathrm{EU}$ 에서 제시하고 있는 $\mathrm{CMR}$ 물질의 판단 기준을 활용하여 석유계 화학물질 중 국내·외 국제기구 및 기관에 서 이미 $\mathrm{CMR}$ (구분1)로 분류한 물질이더라도(그룹A 물질), 그 구성 성분 중 벤젠 $0.1 \%$ 이상 또는 1,3-부타디엔 $0.1 \%$ 이상 또는 DMSO $3 \%$ 이상, 벤조(a)피렌 $0.005 \%$ 이상을 함 유하고 있지 않으면, 그 석유계 $\mathrm{UVCB}$ 물질을 $\mathrm{CMR}$ (구분1) 물질이 아닌 것으로 판단하는 것이다. 다만, 이러한 판단 기 준은 벤젠, 1,3-부타디엔, DMSO, 벤조(a)피렌만을 특정 성 분으로 채택하고 있기 때문에 이 외의 구성 성분 중 $\mathrm{CMR}$ (구분1)로 분류되는 성분이 있음에도 불구하고, 그 석유계 $\mathrm{UVCB}$ 물질이 $\mathrm{CMR}$ 물질이 아닌 것으로 판단될 수 있는 한 계점이 있다.

\subsubsection{2. 국립환경과학원 혼합물의 분류기준을 적용한 판단}

국립환경과학원 고시 '화학물질의 분류 및 표시 등에 관 한 규정, [별표 1] 화학물질의 분류 및 표시사항'에 따른 혼 합물의 분류기준을 적용하여 석유계 $\mathrm{UVCB}$ 물질의 구성 성 분 중 $\mathrm{CMR}$ 물질을 한계농도(발암성/변이원성 구분 1 은 $0.1 \%$, 생식독성 구분 1 은 $0.3 \%$ ) 이상 함유하는 경우 구분 1 에 해 당하여 그 석유계 $\mathrm{UVCB}$ 물질을 $\mathrm{CMR}$ (구분1)물질로 판단 할 수 있다. 현재 유해화학물질로 지정·고시되었거나 '21년 까지 등록하여야할 $\mathrm{CMR}$ 물질로 고시된 물질은 총 506종 ('21년까지 등록하여야 CMR물질 364종 및 [별표 4] '분류. 표시 목록' 중 $\mathrm{CMR}$ (구분 1)로 분류된 물질 142종)인데, 이 러한 판단 기준을 따를 경우, 506종의 화학물질 중 하나라 도 한계농도 이상 함유하고 있는지 각 석유계 화학물질의 구성 성분을 모두 확인해봐야 하는 현실적인 어려움이 있 다. 또한, 506종 외에도 $\mathrm{CMR}$ (구분1)로 분류될 수 있는 석유
Table 6. Priority among air pollutants.

\begin{tabular}{cccc} 
Priority & Chemical name & CAS No. & $\begin{array}{c}\text { No. } \\
\text { Company }\end{array}$ \\
\hline 1 & Formaldehyde & $50-00-0$ & 1,153 \\
\hline 2 & Benzene & $71-43-2$ & 503 \\
\hline 3 & Acrylonitrile & $107-13-1$ & 196 \\
\hline 4 & $1,3-B u t a d i e n e$ & $106-99-0$ & 140 \\
\hline 5 & Ethylene oxide & $75-21-8$ & 75 \\
\hline 6 & $1,2-D i c h l o r o e t h a n e$ & $107-06-2$ & 62 \\
\hline 7 & Propylene oxide & $75-56-9$ & 61 \\
\hline 8 & Vinyl chloride & $75-01-4$ & 34 \\
\hline
\end{tabular}

계 화학물질(단일성분)을 함유할 수 있는데, 이 경우 $\mathrm{CMR}$ (구분1)물질로 확인되지 않을 수 있다는 한계점도 있다.

\subsubsection{3. 기준물질을 확대하여 성분에 따른 판단}

$\mathrm{EU}$ CLP 규정에서 $\mathrm{CMR}$ (구분1)물질을 판단하기 위해 성분· 함량을 확인하는 물질은 벤젠, 1,3 -부타디엔, 벤조(a)피렌, $\mathrm{DMSO}$ 이다.

한편, $\mathrm{EU}$ 에서 석유계 $\mathrm{UVCB}$ 물질에 대한 $\mathrm{CMR}$ 여부를 판단하기 위한 4 종의 특정 물질 선정 근거가 작업자에 대한 역학조사를 토대로 한 것으로 판단된다. 이에, 작업자 노출 을 관리하기 위해 지정된 '작업환경측정대상 유해인자' 해 당 여부와 대기 환경을 관리하기 위해 지정된 '대기오염물 질' 해당 여부를 $\mathrm{CMR}$ 여부의 판단 기준에 적용할 특정 물 질로 지정하는 방안을 검토하였다.

이를 위하여「산업안전보건법」제 125 조(작업환경측정)에 따른 '작업환경측정 대상 유해인자' 및 「대기환경보전법」 제2조(정의)에 따른 '대기오염물질'의 $\mathrm{CMR}$ 여부를 확인하 여 위하여 506종과 비교·분석하였다. 또한, 특정 물질이 너 무 많은 경우 우선순위를 고려하기 위하여 화학물질 통계조 사와도 비교, 분석하여 '작업환경측정 대상 유해인자' 및 '대기오염물질' 중 기 작성된 총 1,785 종의 국내·외 석유계 화학물질과 국내 고시에 따라 $\mathrm{CMR}$ 로 분류된 총 506 종의 화학물질에 해당하며 국내에서 취급하는 기업수가 가장 많 은 우선순위로 화학물질을 선정하였다(Table 5, 6).

\subsection{CMR 판단 기준 활용방안 제시}

앞에서 분류한 석유계 물질의 그룹 중 그룹 $\mathrm{A}$ 는 모두 국 내·외 기준에 따라 $\mathrm{CMR}$ 로 분류된 물질로 유해성 정보를 빨리 확보할 필요가 있는 물질이다. 그러나 $\mathrm{CMR}$ 물질임에 도 사전신고 결과에 따라 30 년까지 유해성 자료가 확보 예 정인 물질이 존재하기도 하며, 이 물질들의 빠른 등록 유도 가 필요하다. 앞에서 제시한 '기준물질을 확대하여 성분에 따른 판단' 방법을 적용하여 특정 물질이 없으면 $\mathrm{CMR}$ 물질 에서 제외하여 본래의 등록 유예기간 안에 등록하게 하는 
Table 7. Components for judging petroleum chemical substances requiring early registration.

\begin{tabular}{|c|c|c|c|c|c|}
\hline \multirow[b]{2}{*}{ No. } & \multirow[b]{2}{*}{ Chemical name } & \multirow[b]{2}{*}{ CAS No. } & \multirow[b]{2}{*}{$\begin{array}{c}\text { Restriction } \\
\text { limits(\%) }\end{array}$} & \multicolumn{2}{|r|}{ Remark } \\
\hline & & & & $\begin{array}{c}\text { EU CLP } \\
\text { ANNEX VI }\end{array}$ & $\begin{array}{l}\text { 'Harmful factors subject to work } \\
\text { environment measurement' and } \\
\text { 'Air pollutants' }\end{array}$ \\
\hline 1 & Benzene & $71-43-2$ & $0.1 \%$ & $\bigcirc$ & 0 \\
\hline 2 & 1,3-Butadiene & $106-99-0$ & $0.1 \%$ & $\bigcirc$ & O \\
\hline 3 & Benzo(a)-pyrene & $50-32-8$ & $0.005 \%$ & $\mathrm{O}$ & \\
\hline 4 & Dimethyl sulfoxide & $67-68-5$ & $3 \%$ & 0 & \\
\hline 5 & Isoprene & $78-79-5$ & $0.1 \%$ & & \\
\hline 6 & Formaldehyde & $50-00-0$ & $0.1 \%$ & & $\bigcirc$ \\
\hline 7 & Acrylonitrile & $107-13-1$ & $0.1 \%$ & & $\bigcirc$ \\
\hline 8 & Ethylene oxide & $75-21-8$ & $0.1 \%$ & & $\bigcirc$ \\
\hline 9 & 1,2-Dichloroethane & $107-06-2$ & $0.1 \%$ & & O \\
\hline 10 & Propylene oxide & $75-56-9$ & $0.1 \%$ & & O \\
\hline 11 & Vinyl chloride & $75-01-4$ & $0.1 \%$ & & O \\
\hline
\end{tabular}

등의 관리방안을 마련하는데 적용될 수 있다. 또한, $\mathrm{CMR}$ 정보를 가지고 분류한 그룹 정보(Table 3)와 범주를 통한 방 법을 통해 화학물질을 취급하는 이는 $\mathrm{CMR}$ 여부를 스크리 닝할 수 있다.

\section{4. 결론}

성분·함량이 항상 일정한 값(범위)으로 확인되지 않는 석 유계 $\mathrm{UVCB}$ 물질의 경우, 원유와 같이 투입되는 원료의 조 성이 원산지에 따라 다양하거나, 같은 제품이라도 설치된 생산공정 설비의 특성에 따라 각각의 구성물질의 성분·함 량을 정확히 파악하는 것은 현실적으로 불가능하다. 범주를 통한 $\mathrm{CMR}$ 판단 방법은 국내 석유계 화학물질, 특히 $\mathrm{UVCB}$ 물질의 성분·함량 등에 대한 분석결과가 있어야 범주화 (Categorization)가 가능한데, 이러한 사전 정보가 아직 충분 히 구축되어 있지 않아 적용하는데 현실적으로 어려움이 있 다. 또한, 혼합물의 분류정보를 정하는 기준을 적용할 때도 모든 $\mathrm{CMR}$ 물질(성분)의 함유여부와 함량을 확인해야 하는 제한점이 있다.

이상과 같은 결과를 토대로 석유계 $\mathrm{UVCB}$ 물질의 $\mathrm{CMR}$ 물질 여부를 판단하기 위해서는 '특정물질 목록과 함량 기 준’이 현재 적용할 수 있는 가장 합리적인 기준으로 판단된 다. 즉, 석유계 $\mathrm{UVCB}$ 물질 중 공정계통도로 추정할 때 특정 물질을 함유하고 있을 것으로 예상되는 경우, $\mathrm{CMR}$ (구분1) 물질로 간주하되, 해당 특정물질이 $0.1 \%$ (생식독성 구분 1 은 $0.3 \%$ ) 미만 함유되었다고 확인되는 경우에는 $\mathrm{CMR}$ (구분1) 물질로 간주하지 않는 것이다. 이때 특정물질은 EU CLP ANNEX VI 그리고 '작업환경측정 대상 유해인자' 및 '대기 오염물질'에서 제시된 물질 중에서 국내 취급업체수가 많은 물질로 선정했다(Table 7).
향후 우리나라에서도 유럽이나 미국처럼 석유계 화학물 질을 범주화한다면 제조·수입자뿐만 아니라 사용자도 유해 성정보를 쉽게 예측할 수 있을 것으로 판단된다. 따라서, 국 내 산업계와 관련 단체·협회에서도 석유계 화학물질의 성 분·함량 등에 대한 범주화를 위한 정보 확보에 보다 적극적 으로 나서야 할 것이다.

\section{References}

1. Act on Registration, Evaluation, etc. of Chemical, Article 10(2018).

2. Ministry of Environment, Existing Chemicals that may Cause or Cause Cancer, Mutations, and Reproductive Abnormalities that must be Registered for up to ' 21 years, 2018-232(2018).

3. C. R. Clark, R. H. McKee, J. J. Freeman, D. Swick, S. Mahagaokar, G. Pigram, L. G. Roberts, C. J. Smulders, P. W. Beatty, A GHS-consistent approach to health hazard classification of petroleum substances, a class of UVCB substances, Regul. Toxicol. Pharmacol., 67(3), 409-420(2013).

4. J. Moon, B. Lee, J.-S. Ra, K.-T. Kim, Predicting PBT and CMR properties of substances of very high concern (SVHCs) using QSAR models, and application for K-REACH, Toxicol. Rep., 7, 995-1000(2020).

5. Chemical Information Processing System, https://kreachportal. me.go.kr, September(2019).

6. CONCAWE Inventory of Petroleum Substances, http://www.con cawe.eu, September(2019).

7. HSPA Defined Substances Per REACH Registration Dossier, https://www.reachcentrum.eu, September(2019).

8. HOPA REACH Consortium Substances, https://hopaconsorti um.com, September(2019).

9. R4CC Inventory of Pure Coal Chemicals and Isomer Mixtures, https://www.r4cc.org, September(2019). 
10. R4CC Inventory of Coal Based UVCBs, https://www.r4cc.org, September(2019).

11. Consortium Substances Managed by LOA, https://loa-reach.com, September(2019).

12. U.S. HPV Challenge Program Substances, https://petroleum hpv.org, September(2019).

13. National Institute of Environmental Research, Designation of Toxic Substances, 2020-7(2020).

14. National Institute of Environmental Research, Classification and Marking of Chemicals, 2019-57(2019).

15. Ministry of Employment and Labor, Criteria for Exposure to Chemicals and Physical Factors, 2020-48(2020).

16. Table of Harmonized Entries in Annex VI to CLP, https://echa.europa.eu, August(2019).

17. OSHA Technical Manual, Safety Hazards, Petroleum Refining Process, https://www.osha.gov, September(2019).

\section{Authors}

\section{Minji Kwon}

Department of Environmental \& Safety Engineering, Ajou University, M.S. Candidate, ORCID (1) 0000-0003-0438-7452

\section{Meejin Kang}

Ministry of Environment, Deputy Director, ORCID (1) 0000-00016364-6691

\section{Keunwon Lee}

Department of Environmental \& Safety Engineering, Ajou University, Associate Professor

\section{Seungho Jung}

Department of Environmental \& Safety Engineering, Ajou University, Professor, ORCID (10 0000-0001-8339-441X 